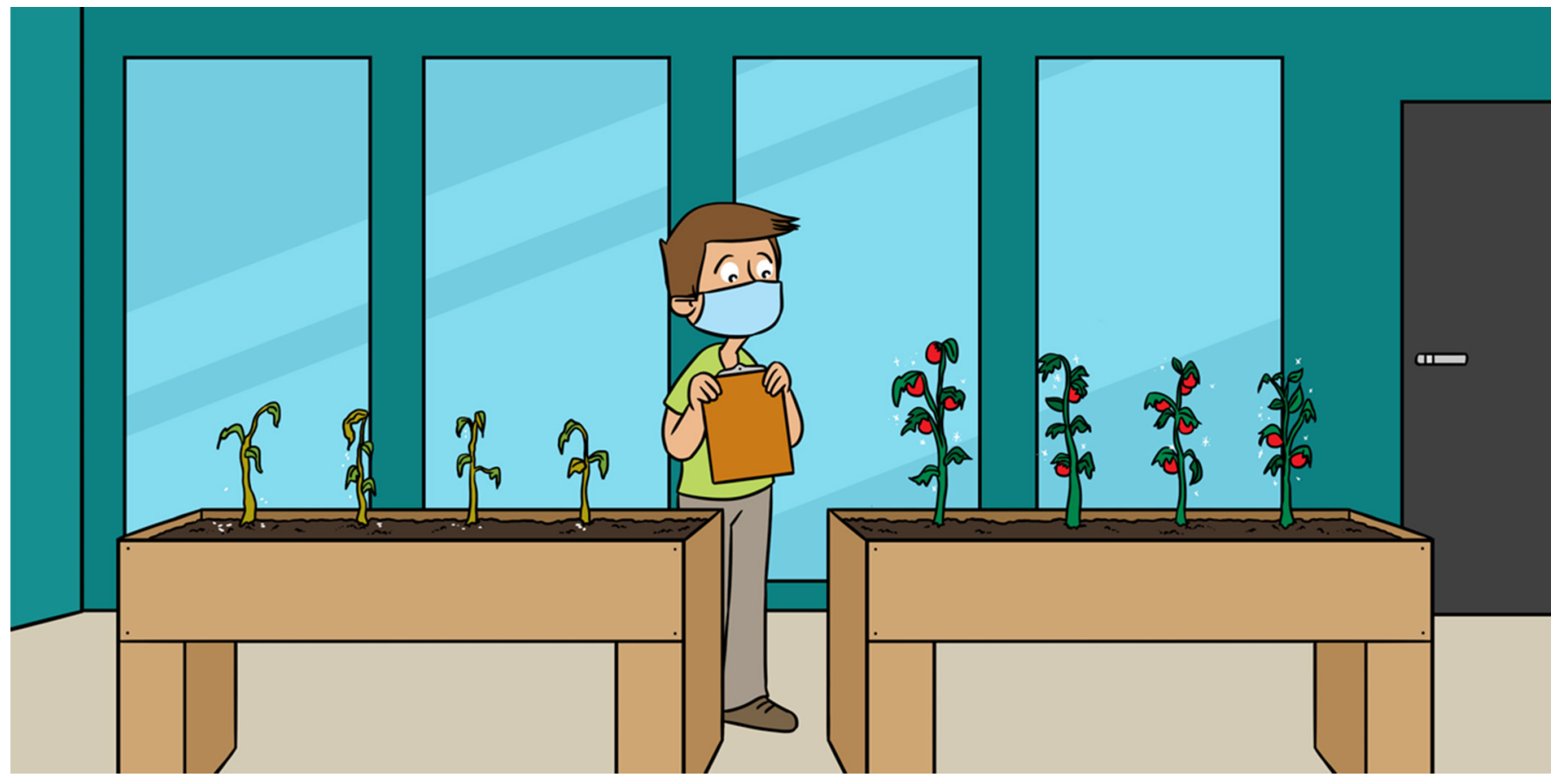

\title{
ENGINEERING PLANTS TO IMPROVE THEIR IMMUNE SYSTEM
}

\section{Meirav Leibman-Markus and Maya Bar*}

The Institute for Plant Protection, Agricultural Research Organization, Volcani Institute, Rishon LeTsiyon, Israel

YOUNG REVIEWERS:

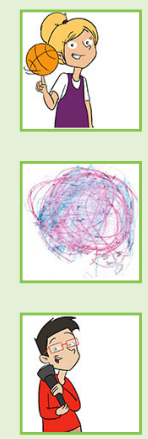

ELUL

AGE: 9

MAYA

AGE: 12

MICHAEL

AGE: 12
Much like humans, plants suffer from all kinds of diseases. In our lab, we study the immune system of plants. Using a technology called CRISPR, which enables us to edit the DNA of different creatures, we made changes in the plant immune system, with the goal of strengthening it. We succeeded in strengthening the plant immune system, and produced plants that are more resistant to diseases. Producing plants with a more active immune system could help us deal with plant diseases and improve agricultural crops.

\section{PLANTS CAN GET SICK}

Plants are the basis of the living world. Look around and try to guess how many products that you use daily are made from plants... you will be surprised! Plant products include the foods we eat, such as vegetables, fruits, nuts, and wheat products ranging from flour and bread to snacks. But not only that-all the animal foods that some of us eat, including meat and animal products like milk or cheese, are dependent on plants, because animals eat plants. Think about 
IMMUNE SYSTEM

The collection of things (organs, cells, molecules, etc.) that defends an organism against the invasion of disease-causing organisms, such as bacteria, viruses, fungi, or parasites.

\section{PROTEIN}

A molecule made of microscopic building blocks called amino acids, which are determined by the sequence of the gene. Proteins can act like tiny machines and perform different tasks. everything related to the wood industry: furniture, paper, and rubber. Cotton textiles are produced from the cotton plant, and some textiles, including silk and wool, are products of animals that feed on plants. These are just some of the examples of how important plants are!

Just like humans, plants can get sick. There are different kinds of bacteria, viruses, fungi, and insects that cause plant diseases. For example: insects eat the plants until they can no longer hold themselves upright, causing them to fall over and die, or, some insects "just" snack on their fruits-and no one wants to eat an apple with a worm in it! Insects and fungi cause the decomposition of plant structures, and viruses can cause the yellowing and destruction of a plant's organs. Sick plants do not grow normally and are not able to obtain nutrients from the ground or energy from sunlight; therefore, they do not produce the leaves, fruits, or seeds that we eat or use in various industries.

Plant diseases cause a yearly destruction of over $60 \%$ of the world's agricultural crops, which include vegetables, fruits, and grains. For this reason, it is important to study and understand plants' immune system to help prevent plant diseases and to decrease damage caused by these diseases. This will help us grow plants that are healthier and produce more yield.

Unlike animals, plants cannot run away from a threat. They are planted in place, and do not have the option to change their environmental conditions. Animals have special proteins, called antibodies, which can identify elements from invaders, like viruses, fungi or bacteria. When the antibodies identify an intruder, among other things, they recruit killing cells, which destroy the intruder. When we receive a vaccine, we are teaching the body to create antibodies against an intruder, which it has not yet met, so that our immune system will respond efficiently when we do encounter that intruder. Plants do not have antibodies or killing cells like people do. The plant immune system uses other methods to defend against diseases and pests [1-4], like the ability to inform neighboring cells about the presence of a disease-causing organism, or the ability to cause an infected cell to "commit suicide" in order to avoid spreading the disease to the rest of the plant. Basically, with some exceptions, each of the plant's cells has these important disease-fighting abilities. Additionally, plants can strengthen the walls of their cells to prevent invasion and can create substances that are toxic to intruders. In our lab, we study the defenses that the plant immune system uses against intruders, and we try to produce plants that are more resistant to diseases.

\section{CAN WE "VACCINATE" PLANTS?}

Some of the research questions in our lab include: "How do plants identify the disease-causing organisms that attack them?"; "Why do 


\section{BIOLOGICAL CONTROL}

An intentional human intervention aimed to eradicate disease-causing organisms, using other organisms. Examples include spreading beetles that feed on other insects that harm crops or using fungi or bacteria that do not cause disease to activate the plant immune system.

\section{DNA}

Deoxyribonucleic acid; a huge molecule present in every cell, which contains the information for creating that organism.

\section{GENE}

A short section of DNA that carries the information that determines a specific trait of the organism. certain organisms, such as the fungus Fusarium graminearum, cause a lethal wilting disease only in wheat and barley, while another fungus, Botrytis cinerea, causes gray mold disease in over 1,400 different plant species?"; and "Why are there tomato plants in our greenhouse that develop a severe disease, causing decomposition and loss of leaves, flowers, and fruits, while other plants near them, of the same species, remain perfectly healthy?"

We can partially control plant disease by spraying plants with chemical substances, but these substances are harmful for us and for the environment, sometimes irreversibly. Therefore, it is extremely important to find other human- and environment-friendly ways to reduce the harm from plant diseases. One of the solutions is biological control, which is the use of living organisms to protect plants. One type of biological control is based on creating a kind of a "vaccine" for the plant, by introducing microorganisms (such as bacteria or fungi) that can activate the plant immune system, but do not cause disease. As a result, the plant's immune system is in a state of "alertness," so that when the plant does encounter the actual disease-causing organism, it will respond more quickly and strongly against it, and therefore will not get as sick.

\section{CRISPR, USING BACTERIAL TRICKS FOR HUMAN BENEFIT}

What if we could "vaccinate" plants by changing their DNA so that their immune system is more active? You may already know that DNA is the genetic material of an organism, made up of many smaller sections called genes, each of which contains the instructions for a different part or tool of the organism. DNA is passed down from parents to their offspring, so any changes made in the DNA of the parent will also be present in the DNA of the offspring. However, how can we make changes to the genes that make up the plant immune system?

Recently, a new technology called CRISPR (which is short for "clustered regularly interspaced short palindromic repeats") was developed [5]. This technology allows scientists to make changes in an organism's DNA, and "edit" its genes. CRISPR is based on a natural phenomenon occurring in the immune system of some bacteria. Scientists discovered the CRISPR system and adapted it for use in other organisms.

Here is how CRISPR works in bacteria: When a virus attacks a bacterium (or any other creature, including a human), it injects its genetic material (for some viruses, it is DNA and for others it is RNA) into the bacterial cell, so that the bacterium will make copies of the virus's genetic material (Figure 1A). This eventually causes the death of the bacterium. CRISPR is a section of DNA present in certain bacteria that is used to defend them against bacteria-attacking 
Figure 1

\section{CRISPR}

protects bacteria from viral attack. (A) A virus attaches to a bacterium and injects its genetic material into it. (B) The bacterium inserts pieces of the virus's genetic material into its CRISPR library. (C) The bacterium creates CRISPR-segments from its CRISPR library, along with scissor-like proteins. (D) If a CRISPR-segment matches the genetic material of an invading virus, it recruits the scissor-like proteins, which cut up the viral genetic material, ending the virus's attack.

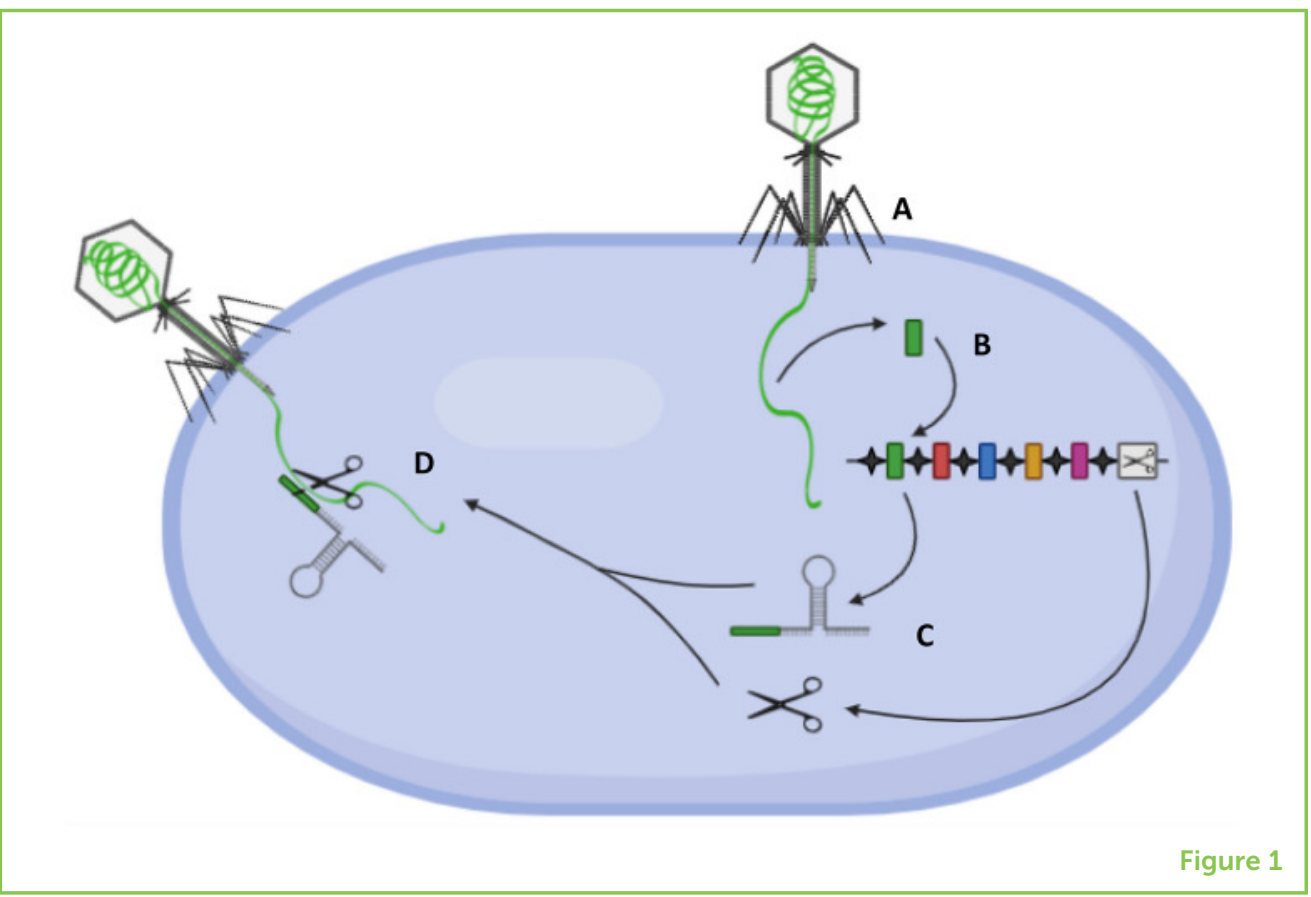

viruses. These bacteria developed an acquired immune system that learns to identify genetic material of viruses and destroy it, and this knowledge is inherited to the bacterium's offspring (daughter cells). CRISPR is actually a "library" of DNA fragments that were cut from the genetic material of all sorts of viruses that the bacterium, or one of its ancestors, met in the past. Along with this library of previously encountered virus's DNA fragments, the bacteria also has genes for the production of scissors-like proteins that can chop up genetic material (Figure 1B). The bacterium creates CRISPR-segments from each virus-specific fragment of the CRISPR library, and these segments float around in the cell, waiting to protect the bacterium from any future viral infection (Figure 1C). When the bacterium is infected with a virus, the CRISPR-segment that matches the genetic material of that particular virus sticks to the viral genetic material, identifies that it is from a virus, and tells the scissors-like proteins to chop up the virus's genetic material (Figure 1D), so that no new viruses are produced!

Today, scientists have learned how to use the CRISPR system from bacteria to accurately identify and change chosen regions of the DNA of any organism-plants, animals, or human cells. They do this by inserting a CRISPR-like system into the organism who's DNA they want to change; only this time, instead of a library of viral genetic material fragments, they put a DNA segment of the gene they want to change. This way the CRISPR-segment will stick to that gene and the scissors-like proteins will cut it. When the organism will try to repair the cut, it will lead to a change in that gene. And this is exactly what we did to boost the immune system of plants! 


\section{Figure 2}

Tomato leaves infected with gray mold $(B$. cinerea) and the moth T. absoluta. (A) Tomato leaves of untreated plants are susceptible and develop severe symptoms. (B) The same tomato species, in which we used the CRISPR technology to change an important gene of the plant's immune system. The CRISPRed plants are more resistant and barely have any symptoms.

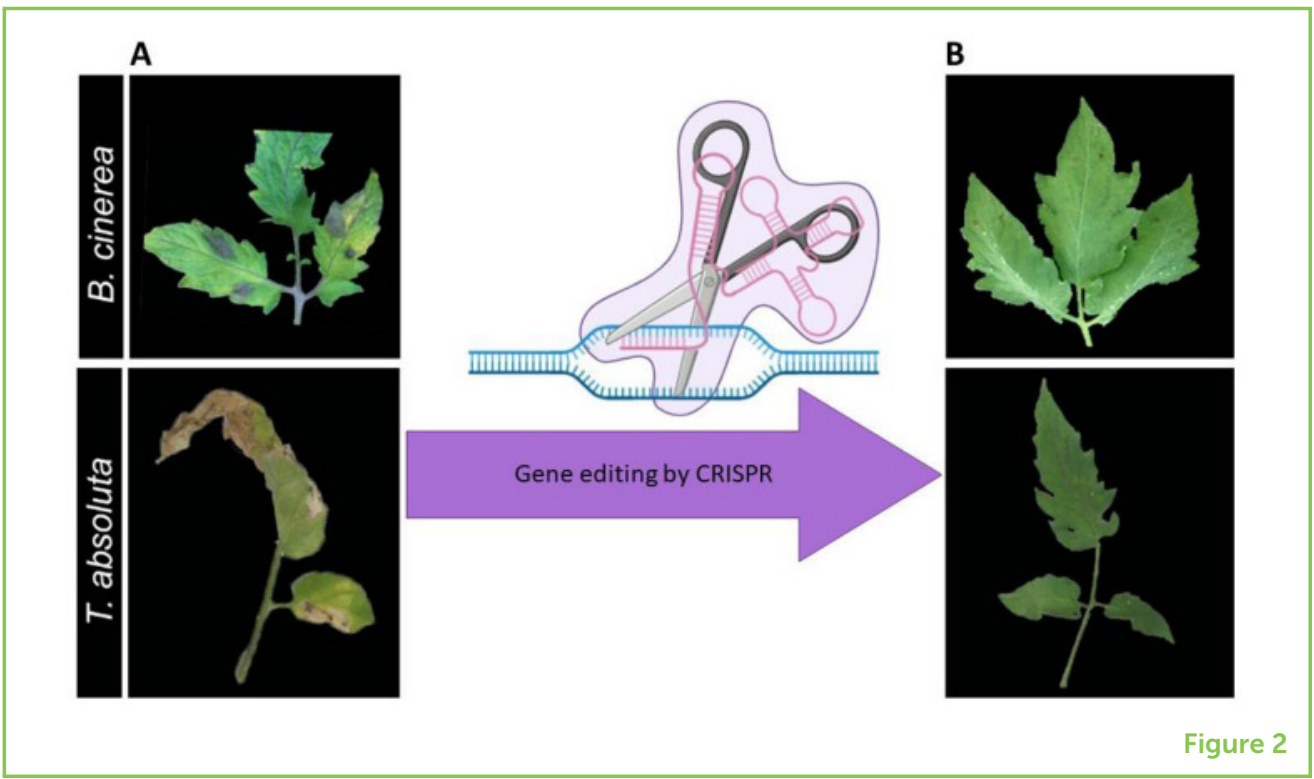

\section{CRISPR, LET US ENGINEER A SUPER PLANT!}

In our lab, we study tomato plants to learn about the immune system of plants in general. We aim to create a tomato plant that is more resistant to diseases and reduce the loss of crops and the need to use chemical control substances. To achieve this goal, we used the CRISPR technology on an important gene involved in the tomato plant's immune system, and changed it [6]. This gene takes part in the recognition of a disease factor, and in the activation of the plant's immune system in response. Normally, without an invader, the plant immune system is not active. Due to the change we made in this gene using CRISPR, it acts as if it senses an invader all the time. In fact, using CRISPR technology, we changed the tomato plant's DNA so that the plant's immune system was always alert, even in the absence of a disease-causing organism! In a way, the plant is "vaccinated." Since the plant's immune system is pre-activated, when the plant is attacked, it can defend itself more quickly and strongly. As a result, the plant will get less or no disease. The activation of the plant's immune system in this way does not take the plant's energy away from the production of fruits, so the crop yield is not reduced.

We tested whether this "vaccination" of the tomato plant's immune system using CRISPR technology was able to protect the plant from diseases. Normal tomato plants are susceptible to the gray mold fungus ( $B$. cinerea) and to a harmful moth called Tuta absoluta (Figure 2A). The plants in which we performed the genetic change were more resistant to diseases caused by these two organisms, and therefore the amount of plant tissue that was harmed by the fungus or the moth was much smaller (Figure 2B). 


\section{SAVING THE PLAN(E)T}

Plants are susceptible to many different diseases that can damage or kill them and decrease the amount of yield that they produce for humans and other animals. By using the gene-editing technology called CRISPR, we were able to change an important immune related gene. This change is boosting the immune systems of plants, resulting in a reduction in both the decreased crop yields caused by plant diseases, and the environmental damage that results from the use of chemical control substances. Furthermore, if we can determine which immune mechanisms are activated in the resistant plants in our experimental systems, we will gain new insights into the function of the immune system of plants, a topic that is still not completely understood. In the future, the knowledge we gain from using the CRISPR technology in various agricultural species will help us to increase crop production, toward ensuring a sufficient supply of all the plant-derived products for the use of humans and animals on earth.

\section{ORIGINAL SOURCE ARTICLES}

(1) Leibman-Markus, M., Pizarro, L., Schuster, S., Daniel Lin, Z. J., Gershony, O., Bar, M., et al. 2018. The intracellular nucleotide-binding leucine-rich repeat receptor (SINRC4a) enhances immune signaling elicited by extracellular perception. Plant Cell Environ. 51:2313-27. doi: $10.1111 /$ pce.13347

(2) Pizarro, L., Leibman-Markus, M., Gupta, R., Kovetz, N., Shtein, I., Bar, E., et al. 2020. A gain of function mutation in SINRC4a enhances basal immunity resulting in broad-spectrum disease resistance. Commun. Biol. 3:404. doi: 10.1038/s42003-020-01130-w

\section{REFERENCES}

1. Alhoraibi, H., Bigeard, J., Rayapuram, N., Colcombet, J., and Hirt, H. 2019. Plant immunity: the MTI-ETI model and beyond. Curr. Issues Mol. Biol. 30:39-58. doi: $10.21775 /$ cimb.030.039

2. Flor, H. H. 1971. Current status of gene-for-gene concept. Annu. Rev. Phytopathol. 9:275-96. doi: 10.1146/annurev.py.09.090171.001423

3. Jones, J. D., and Dangl, J. L. 2006. The plant immune system. Nature 444:323-9. doi: $10.1038 /$ nature05286

4. Medzhitov, R., and Janeway, C. A. Jr. 1997. Innate immunity: the virtues of a nonclonal system of recognition. Cell 91:295-8.

5. Jinek, M., Chylinski, K., Fonfara, I., Hauer, M., Doudna, J. A., and Charpentier, E. 2012. A programmable dual-RNA-guided DNA endonuclease in adaptive bacterial immunity. Science 337:816-21. doi: 10.1126/science.1225829

6. Pizarro, L., Leibman-Markus, M., Gupta, R., Kovetz, N., Shtein, I., Bar, E., et al. 2020. A gain of function mutation in SINRC4a enhances basal immunity resulting 
in broad-spectrum disease resistance. Commun. Biol. 3:404.

doi: 10.1038/s42003-020-01130-w

SUBMITTED: 29 December 2020; ACCEPTED: 27 April 2021;

PUBLISHED ONLINE: 28 May 2021

EDITED BY: Idan Segev, Hebrew University of Jerusalem, Israel

CITATION: Leibman-Markus M and Bar M (2021) Engineering Plants to Improve Their Immune System. Front. Young Minds 9:647187. doi: 10.3389/frym.2021. 647187

CONFLICT OF INTEREST: The authors declare that the research was conducted in the absence of any commercial or financial relationships that could be construed as a potential conflict of interest.

COPYRIGHT () 2021 Leibman-Markus and Bar. This is an open-access article distributed under the terms of the Creative Commons Attribution License (CC BY). The use, distribution or reproduction in other forums is permitted, provided the original author(s) and the copyright owner(s) are credited and that the original publication in this journal is cited, in accordance with accepted academic practice. No use, distribution or reproduction is permitted which does not comply with these terms.

\section{YOUNG REVIEWERS}

\section{ELUL, AGE: 9}

Elul likes animals, she plays the recorder, and she knows all types of dogs.

\section{MAYA, AGE: 12}

My name is Maya and I like reading, writing, and playing the flute. I also like algebra and the fact that there is a whole infinite universe that we can study.

\section{MICHAEL, AGE: 12}

Michael likes soccer, guitar, animals, chemistry, history, and politics.

\section{AUTHORS}

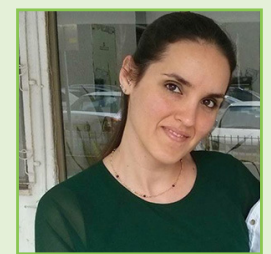

\section{MEIRAV LEIBMAN-MARKUS}

Meirav is a research assistant at the Volcani Institute. Since she was little, she always liked asking questions and solving riddles. The most interesting riddles are the ones nature created. Therefore, to try to find out the secrets of nature, and plants in particular, Meirav chose to study biology, and got her doctorate in biology at Tel 


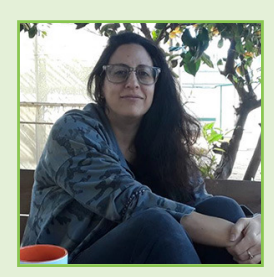

Aviv University. Today, she works in the lab of Maya Bar at the Volcani Institute, trying to find out how plants defend themselves against pests and how we can produce more resistant, healthier plants.

\section{MAYA BAR}

Maya is a researcher at the Volcani Institute. She always knew she would become a biologist, and started studying plants by chance, when an instructor in one of the courses she took at University suggested that she work in a lab that studied plant molecular biology. Later on, Maya opened her own lab at the Volcani Institute. Maya's lab researches the plant immune system, with one of its goals being the production of disease-resistant plants. Maya and Meirav are also good friends, and they enjoy conducting research together. https://mayapiff.wixsite.com/barlab. *mayabar@volcani.agri.gov.il 